\title{
Incidence and Prognosis of Acute Renal Failure in Patients with Severe Sepsis and Septic Shock
}

\section{Madiha M Zidan, Ahmed A El-Shebiny, Rafeek Y Atalla, Mohamed A Mohamed}

Department of Anesthesia, Intensive Care and Pain Management

Faculty of Medicine, Ain Shams University

Corresponding author: Mohamed A Mohamed; Mobile: 01002963468; Email: malek.hikal@ gmail.com ABSTRACT

Background: Sepsis is a life-threatening condition that arises when the body's response to infection causes injury to its own tissues and organs. Acute kidney injury (AKI), previously called acute renal failure (ARF) is an abrupt loss of kidney function, Generally it occurs because of damage to the kidney tissue caused by decreased kidney blood flow (Kidney ischemia) from any cause. AKI may lead to a number of complications, including metabolic acidosis, high potassium levels, uremia, changes in body fluid balance, and effects on other organ systems, including death. Aim: The aim of the study is to show the incidence and prognosis of acute renal failure in patients with sepsis and septic shock. Patients and methods: This prospective randomized study was conducted on patients who were admitted to ICU in Ain Shams University Hospitals. Forty patients were included in this study and an informed written consent was obtained from patients and/or relatives. All patients were adult, more than 18 years old, admitted to ICU suffering from severe sepsis or had septic shock for monitoring, management and follow up to their condition in period of six months. All patients were more than 18 years old that were critically ill either in severe sepsis or had septic shock. We excluded patients less than 18 years old, patient or relatives who refused to be included in this study, and if he/she has a history of previous kidney troubles or dysfunction. All patients were subjected to assessment of the demographic data of the patient, causes and site of infection, pathogenic bacteria as declared by different cultures, APACHE 2 score on admission, all patients were managed as declared by ICU, protocol for septic patients, hemodynamic monitoring was done daily, routine lab investigation daily, coagulation profile had to be done on days $0,3,7$ of admission, SOFA score on days $0,3,7$ of admission, renal functions include blood urea and creatinine clearance test had to be done daily, any deterioration of renal function was reported, and if the patient was in need for renal replacement therapy or dialysis, this would be reported. Results: Forty patients were included in this study, their ages with a mean of $58.37 \pm 15.66$ years. 23 patients $(57.5 \%)$ were males and 17 patients $(42.5 \%)$ were females. The most frequent risk factors were hypertension (62.5\%) followed by diabetes $(52.5 \%)$. The incidence of AKI was $60 \%$ of patients and the need for renal replacement therapy (RRT) was $9(22.5 \%)$. Outcome of admitted patients in ICU was $23(57.5 \%)$ survived patients and $17(42.5 \%)$ non-survived patients. The study showed that there were no statistical significant differences between AKI and Non-AKI patients except for; gender (male), BMI, gram -ve bacterial infection, creatinine, BUN, creatinine clearance, history of ACE administration, use of vasopressors, APACHE II score at admission and mortality were statistically significant $(p<0.05)$. Conclusion: The incidence of AKI was $60 \%$ of patients in our study. The development of septic AKI adversely affected clinical outcomes. Moreover, the severity of AKI was associated with increased shortterm mortality as observed in ICU patients. The study showed that there were no statistical significant differences between AKI and Non-AKI patients except for; gender (male), BMI, gram -ve bacterial infection, creatinine, BUN, creatinine clearance, history of ACE administration, use of vasopressors, APACHE II score at admission and mortality were statistically significant $(\mathrm{p}<0.05)$.

Key words: acute renal failure, severe sepsis, septic shock

\section{INTRODUCTION}

Both sepsis and acute kidney injury (AKI) are diseases of major concern in critically ill patients. Severe sepsis is often complicated by AKI ${ }^{(1)}$. The overall incidence of septic AKI (SAKI) among all intensive care unit (ICU) admissions ranges between 15 and $20 \%{ }^{(\mathbf{1})}$.

Large studies in critically ill patients convincingly demonstrated the "intimate" bond between AKI and sepsis. For instance, the BEST Kidney and FINNAKI studies, which covered different time periods, both

Received 14/3/2018

Accepted 24/3/2018 reported AKI in up to half of the septic patients ${ }^{(3)}$.

Sepsis is a life-threatening condition that arises when the body's response to infection causes injury to its own tissues and organs. Common signs and symptoms include fever, increased heart rate, increased breathing rate, and confusion. There also may be symptoms related to a specific infection, such as a cough with pneumonia, or painful urination with a kidney infection. In the very young, old, and immuno-compromised people, there may be no symptoms of a specific infection and the body temperature may be low or normal, rather than high ${ }^{(2)}$. 
Severe sepsis is sepsis causing poor organ function or insufficient blood flow. Insufficient blood flow may be evident by low blood pressure, high blood lactate, or low urine output. Septic shock is low blood pressure due to sepsis that does not improve after reasonable amounts of intravenous fluids are given ${ }^{(3)}$.

Acute kidney injury (AKI), previously called acute renal failure (ARF) is an abrupt loss of kidney function. Generally it occurs because of damage to the kidney tissue caused by decreased kidney blood flow (kidney ischemia) from any cause (e.g., low blood pressure), exposure to substances harmful to the kidney, an inflammatory process in the kidney, or an obstruction of the urinary tract that impedes the flow of urine ${ }^{(4)}$.

AKI may lead to a number of complications, including metabolic acidosis, high potassium levels, uremia, changes in body fluid balance, and effects on other organ systems, including death ${ }^{(29)}$.

\section{AIM OF THE WORK}

The aim of the study is to show the incidence and prognosis of acute renal failure in patients with sepsis and septic shock

\section{PATIENTS AND METHODS}

This is a prospective randomized study that was conducted on patients who admitted to ICU in Ain Shams University Hospitals. Forty patients were included in this study and an informed written consent was obtained from patients and /or relatives.

\section{Inclusion Criteria}

All patients were more than 18 years old that were critically ill either in severe sepsis or had septic shock

\section{Exclusion Criteria}

- Patients less than 18 years old

- Patient or relatives who refused to be included in this study

- Patient having a history of previous kidney troubles or dysfunction

The diagnosis of severe sepsis, and septic shock was established according to the definitions of the American College of Chest Physicians Consensus Conference (5). All patients received standard supportive treatment following recommendations of the Surviving Sepsis Campaign released in 2016 (6)

Sepsis diagnosis requires the presence of infection (which can be proven or suspected) and 2 or more of the following criteria:
- Hypotension (systolic blood pressure < 90 $\mathrm{mm} \mathrm{Hg}$ or fallen by $>40$ from baseline, mean arterial pressure $<70 \mathrm{~mm} \mathrm{Hg}$ ).

- Mottled skin.

- Decreased capillary refill of nail beds or skin.

- Fever $>38.3^{\circ} \mathrm{C}$ or $101^{\circ} \mathrm{F}$.

- Hypothermia $<36^{\circ} \mathrm{C}$ core temperature $\left(<96.8^{\circ} \mathrm{F}\right)$.

- Heart rate $>90 \mathrm{bpm}$.

- Tachypnea.

- Change in mental status.

- Acute drop in urine output $(<0.5 \mathrm{ml} / \mathrm{kg} / \mathrm{hour}$ for at least 2 hours despite fluid resuscitation, or about $35 \mathrm{ml} /$ hour for a 70 $\mathrm{kg}$ person).

- Significant edema or positive fluid balance (>20 mL/kg over 24 hours).

- Absent bowel sounds (ileus).

- Lactate > $1 \mathrm{mmol} / \mathrm{L}$.

- Arterial hypoxemia $\left(\mathrm{PaO}_{2} / \mathrm{FiO}_{2}<300\right)$.

- White blood cell count $>12,000$ or less than 4,000 , or with $>10 \%$ "bands" (immature forms).

- Elevated C-reactive protein in serum (according to lab's cutoffs).

- Elevated procalcitonin in serum (according to lab).

- Creatinine increase $>0.5 \mathrm{mg} / \mathrm{dL}$.

- INR $>1.5$ or APTT $>60$ seconds.

- Platelet count < 100,000.

- High bilirubin (total bilirubin $>4 \mathrm{mg} / \mathrm{dl}$ ).

- Hyperglycemia (>140 mg/dL) in someone without diabetes.

\section{Study design:}

All patients were subjected to the followings:

1. Full history: including personal data, special habits as smoking, and comorbidities as diabetes, hypertension, renal impairment or cardiac disease.

2. Hemodynamic monitoring: Daily hemodynamic monitoring of the patients:

- Arterial blood pressure

- Heart rate

- Respiratory rate

- Temperature

- Urine output

- Central venous pressure (CVP) measurement

3. Daily clinical examination: daily full clinical examination

4. Lab profile: Routine laboratory investigations on the day of admission and during stay in ICU: 
- CBC, serum electrolytes

- Liver function tests

- Coagulation profile

- Kidney function tests

- Blood gases

- Cultures and sensitivity according to source of sepsis

5. Radiological

- CXR, some patients underwent CT chest, abdomen U/S \& echo

6. Early Goal directed therapy will be initiated for all patients:

- Early empirical broad spectrum antibiotics

- Aiming mean blood pressure > 65 mmHG

- Aiming CVP 8-12 cm $\mathrm{H}_{2} \mathrm{O}$

- Aiming urinary output (UOP) 0.5-1 $\mathrm{ml} / \mathrm{kg} /$ hour

7. Patients data were collected as regard

- Causes of admission.

- Infection Data

- Infection site (pulmonary, genitourinary, abdomen and surgical wound).

- Pathogenic bacteria (Gram +ve, -ve Bacteria and fungi) detected by cultures from (blood, urine, sputum and wound swap)

- Incidence of acute kidney injury and need for renal replacement therapy (RRT)

- Morbidity and Mortality.

- $\quad$ Length of ICU Stay.

8. Scoring System: At ICU admission, severity of the illness was evaluated by the Acute Physiology and Chronic Health Evaluation (APACHE) II score, considering the worst data point for the first 24 hours in the ICU (8). Failure of organs and severity of multiple organ dysfunction syndromes was assessed by the Sequential Organ Failure Assessment (SOFA) scale ${ }^{(9)}$.

9. Follow-up for evaluating acute kidney injury (AKI) was done during hospital stay; AKI was defined as per the KDIGO AKI guideline ${ }^{(7)}$ : increase in serum creatinine by $0.3 \mathrm{mg} / \mathrm{dL}$ within $48 \mathrm{~h}$ or increase in serum creatinine to 1.5 times baseline. AKI were classified as: stage I AKI when serum creatinine increased to 1.5-1.9 times from baseline levels, stage II - increase in serum creatinine to 2.0 2.9 times baseline and stage III - increase in serum creatinine to $>3.0$ time's baseline including initiation of renal replacement

therapy. Also high serum urea, potassium levels, metabolic acidosis and low urine output are indicators of AKI occurrence.

10. All patients were managed with fluid therapy, antibiotics, RRT and other supportive treatment according to:

- Surviving Sepsis Campaign: International Guidelines for Management of Sepsis and Septic Shock 2016

- KDIGO AKI Work Group guidelines 2012

\section{The statistical analysis}

- Quantitative data were expressed using mean and standard deviation (SD) while qualitative data were expressed in frequency and percent.

- Comparison of variables between the study groups and its significance was done using $\mathrm{P}$ value. $\mathrm{P}$ value was considered significant if less than 0.05 .

- All statistical calculations were done using computer programs Microsoft Excel 2007 (Microsoft Corporation, NY, and USA) and SPSS (Statistical Package for the Social Science; SPSS Inc., Chicago, IL, USA) version 23 for Microsoft Windows. (Student t test and Chi square (x2) test were used)

\section{RESULTS}

Table (1): Baseline Characteristics of Study

Patients.

\begin{tabular}{|c|c|}
\hline $\begin{array}{l}\text { Baseline Characteristics n (\%) } \\
\text { of Study Patients } 40\end{array}$ & Mean \pm SD \\
\hline Age (years) & $58.37 \pm 15.66$ \\
\hline $\begin{array}{l}\text { Male } 23(57.5 \%) \\
\text { Female } 17(42.5 \%) \\
\text { BMI kg/m } \\
\text { Risk factors } \\
\text { Smoking } 19(47.5 \%) \\
\text { Dyslipidemia } 16(40 \%) \\
\text { DM } 21(52.5 \%) \\
\text { Hypertension 25(62.5\%) } \\
\text { Admission category } \\
\text { Medical 34 (85\%) } \\
\text { Surgical 6 }(15 \%) \\
\text { Infection category } \\
\text { Community 21 } 152.5 \%) \\
\text { Hospital acquired } 19(47.5 \%)\end{array}$ & $23.88 \pm 2.28$ \\
\hline \multicolumn{2}{|c|}{$\begin{array}{l}\text { BMI; body mass index, DM;diabetes mellitus } \\
\text { Table ( } 1) \text { shows that } 40 \text { patients were } \\
\text { included in this study. The mean of their ages } \\
\text { was } 58.37 \pm 15.66 \text { years. } 23 \text { patients }(57.5 \%) \\
\text { were males and } 17 \text { patients }(42.5 \%) \text { were } \\
\text { females. The most frequent risk factors were } \\
\text { hypertension }(62.5 \%) \text { followed by diabetes }\end{array}$} \\
\hline
\end{tabular}


(52.5\%) beside other risk factors as smoking and dyslipidemia. The patients admitted after surgical interventions were $6(15 \%)$ or for medical reasons $34(85 \%)$. The patients admitted with infection category as community acquired were $21(52.5 \%)$ and hospital acquired infections 19 (47.5\%).

Table (2): Comorbidities Characteristics of studied patients

\begin{tabular}{|l|c|c|}
\hline \multicolumn{1}{|c|}{ Comorbidities } & N & \% \\
\hline COPD or chest diseases & 10 & $25 \%$ \\
\hline Liver diseases & 3 & $7.5 \%$ \\
\hline Malignancy & 2 & $5 \%$ \\
\hline $\begin{array}{l}\text { Previous sugical } \\
\text { intervention }\end{array}$ & 3 & $7.5 \%$ \\
\hline
\end{tabular}

IHD; ischemic heart disease, COPD; chronic obstructive airway diseases

In table (2): Comorbidities in the studied patients were mostly COPD or chest diseases $25 \%$, previous surgery $7.5 \%$, liver disease $7.5 \%$. The least comorbidities were malignancy $(5 \%)$.

Table (3): Laboratory values on admission and day 1 of the study group

\begin{tabular}{|l|c|}
\hline \multicolumn{1}{|c|}{ Parameters } & Mean \pm SD \\
\hline Hemoglobin & $10.8 \pm 2.4$ \\
\hline Hematocrit & $33.1 \pm 5.7$ \\
\hline Platelet count & $218.8 \pm 50.6$ \\
\hline Total leukocytic count & $22.4 \pm 5.13$ \\
\hline Blood Urea nitrogen (BUN) & $46.35 \pm 10.24$ \\
\hline Creatinine & $2.26 \pm 0.5$ \\
\hline Creatinine clearance & $47.85 \pm 5$ \\
\hline SGOT & $69.2 \pm 15.21$ \\
\hline SGPT & $71 \pm 15.02$ \\
\hline Albumin & $3.0 \pm 0.5$ \\
\hline Total bilirubin & $1.5 \pm 0.3$ \\
\hline Direct bilirubin & $0.7 \pm 0.1$ \\
\hline LDH & $156.4 \pm 35.2$ \\
\hline PT & $14.0 \pm 2.6$ \\
\hline PTT & $28.2 \pm 3.5$ \\
\hline INR & $1.3 \pm 0.22$ \\
\hline Na & $134.8 \pm 31.25$ \\
\hline K & $3.92 \pm 0.96$ \\
\hline Calcium & $8.5 \pm 2.10$ \\
\hline Magnesium & $1.8 \pm 0.31$ \\
\hline INR; international normalized ratio, PT; prothrombin time, PTT; \\
\end{tabular}

Table 3 shows laboratory mean values of $\mathrm{CBC}$, liver function, kidney function, coagulation profile and serum electrolytes in the studied patients.
Table (4): Source of infection in the studied patients

\begin{tabular}{|l|c|c|}
\hline Source of infection & $\mathbf{N}$ & $\boldsymbol{\%}$ \\
\hline Abdominal & 4 & $10 \%$ \\
\hline Respiratory & 20 & $50 \%$ \\
\hline Skin and soft tissues & 3 & $7.5 \%$ \\
\hline Mixed & 10 & $25 \%$ \\
\hline Others & 3 & $7.5 \%$ \\
\hline
\end{tabular}

In table (4): Sources of infection in the studied patients were mostly respiratory $50 \%$ then mixed $25 \%$ and. The least sources of infection were abdominal $10 \%$, skin and soft tissues $7.5 \%$ and others (infection from central venous line) $7.5 \%$.

Table (5): Positive cultures in the studied patients

\begin{tabular}{|c|c|c|}
\hline Positive cultures & n & \% \\
\hline Gram +ve only & 5 & $12.5 \%$ \\
\hline Gram -ve only & 19 & $\mathbf{4 7 . 5 \%}$ \\
\hline Polymicrobial & 16 & $\mathbf{4 0 \%}$ \\
\hline
\end{tabular}

In table (5): infection in the studied patients was mostly gram -ve only $21(45.6 \%)$ and Poly-microbial 20 (43.47\%). The least was gram +ve only $5(10.9 \%)$.

Table (6): Types of organisms in culturepositive infected patients

\begin{tabular}{|c|l|c|}
\hline \multicolumn{2}{|c|}{ Types of organisms } & $\begin{array}{c}\text { Frequency } \\
(\%)\end{array}$ \\
\hline \multirow{4}{*}{$\begin{array}{c}\text { Gram- } \\
\text { positive }\end{array}$} & Staphylococcus aureus & $7.5 \%$ \\
\cline { 2 - 3 } & MRSA & $5 \%$ \\
\cline { 2 - 3 } & $\begin{array}{l}\text { Staphylococcus } \\
\text { epidermidis }\end{array}$ & $\begin{array}{l}\text { Streptococcus } \\
\text { pneumoniae }\end{array}$ \\
\cline { 2 - 3 } & Enterococcus & $10 \%$ \\
\cline { 2 - 3 } & Others & $2.5 \%$ \\
\hline \multirow{4}{*}{$\begin{array}{c}\text { Gram- } \\
\text { negative }\end{array}$} & Pseudomonas species & $2.5 \%$ \\
\cline { 2 - 3 } & Escherichia coli & $20 \%$ \\
\cline { 2 - 3 } & Klebsiella species & $25 \%$ \\
\cline { 2 - 3 } & Proteus mirabilis & $27.5 \%$ \\
\cline { 2 - 3 } & Ecinetobacter species & $10 \%$ \\
\cline { 2 - 3 } & Haemophilus & $5 \%$ \\
\hline influenzae & $2.5 \%$ \\
\cline { 2 - 3 } & Others & $5 \%$ \\
\hline Fungi & Candida & $2.5 \%$ \\
\hline
\end{tabular}

MRSA; Methicillin-resistant staphylococcus aureus.

In table 6: in gram positive bacteria, staphylococcus aureus and streptococcus pneumonia were more prevalent $(7.5 \%$ and $10 \%$ respectively), MRSA, staphylococcus Epidermidis 5\% each, and enterococcus and others were $2.5 \%$ each. In gram negative bacteria, Escherichia coli and Klebsiella 
species were more prevalent $(27.5 \%$ and $25 \%$ respectively). Pseudomonas species, Proteus mirabilis, Acinetobacter species, Haemophilus influenzae, nterobacter and others were $20 \%, 10 \%, 5 \%, 5 \%, 2.5 \%$ and $2.5 \%$ respectively. Fungal infection was caused by candida in $17.5 \%$ patients.

Table (7): Follow-up parameters in ICU in the studied patient

\begin{tabular}{|c|c|c|c|}
\hline \multicolumn{2}{|c|}{$\begin{array}{l}\text { Follow-up parameters in } \\
\text { ICU }\end{array}$} & Mean \pm SD & n \% \\
\hline \multicolumn{2}{|c|}{ GCS at admission (Points) } & $10.30 \pm 3.42$ & \\
\hline \multicolumn{2}{|c|}{$\begin{array}{l}\text { SOFA score at admission } \\
\text { (Points) }\end{array}$} & $7.6 \pm 3.11$ & \\
\hline \multicolumn{2}{|c|}{$\begin{array}{l}\text { APACHE II scoreat } \\
\text { admission (Points) }\end{array}$} & $23.87 \pm 8.26$ & \\
\hline \multicolumn{2}{|c|}{ Mechanical ventilations } & & $1845 \%)$ \\
\hline \multicolumn{2}{|c|}{ Length of ICU stay (days) } & $9.85 \pm 6.37$ & \\
\hline \multicolumn{2}{|c|}{$\begin{array}{l}\text { Incidence of acute kidney } \\
\text { injury (AKI) }\end{array}$} & & $24(60 \%)$ \\
\hline \multicolumn{2}{|c|}{$\begin{array}{l}\text { Response to medical } \\
\text { therapy }\end{array}$} & & $20(50 \%)$ \\
\hline \multicolumn{2}{|c|}{$\begin{array}{l}\text { Need for renal } \\
\text { replacement } \\
\text { therapy }(\text { RRT })\end{array}$} & & $9(22.5 \%)$ \\
\hline \multirow{2}{*}{$\begin{array}{l}\text { Outcome in } \\
\text { ICU }\end{array}$} & Survival & & $23(57.5 \%)$ \\
\hline & Mortality & & $17(42.5 \%)$ \\
\hline
\end{tabular}

In table (7): mean of GCS at admission was $10.30 \pm 3.42$ (Points). Means of SOFA score and APACHE II score at admission was 7.6 \pm 3.11 and $23.87 \pm 8.26$ points respectively. 18 (45\%) patients were mechanically ventilated and their mean length of ICU stay was $9.85 \pm 6.37$ days. The incidence of AKI was $60 \%$ of patients and the need for renal replacement therapy (RRT) was $9(22.5 \%)$. Outcome of admitted patients in ICU was $23(57.5 \%)$ survived patients and $17(42.5 \%)$ non-survived patients.

Table (8): Comparison between AKI and Non-AKI patients

\begin{tabular}{|c|c|c|c|c|}
\hline Baseline & $n-40$ & $\begin{array}{c}\text { AKI } \\
n=24(60 \%)\end{array}$ & \begin{tabular}{|c|} 
Non-AKI \\
$n=16(40 \%)$
\end{tabular} & P.yalue \\
\hline Study Patients & $11=40$ & $\begin{array}{c}\text { Mean } \pm \text { SD } \\
\text { or n \% } \\
\end{array}$ & $\begin{array}{c}\text { Mean } \pm \text { SD } \\
\text { or n \% }\end{array}$ & P-vadue \\
\hline \begin{tabular}{|l} 
Age (years) \\
Gender (Male) \\
BMI kg/m² \\
\end{tabular} & $23(57.5 \%)$ & $\begin{array}{l}59.81 \pm 15.4 \\
15(62.5 \%) \\
24.80 \pm 2.51 \\
\end{array}$ & $\begin{array}{c}57.41 \pm 16.01 \\
8(50 \%) \\
23.27 \pm 1.09\end{array}$ & $\begin{array}{c}0.64 \\
\mathbf{0 . 0 4 5}^{*} \\
\mathbf{0 . 0 2 8}^{*} \\
\end{array}$ \\
\hline Risk factors & & & & \\
\hline$\overline{\text { Smoking }}$ & $19(47.5 \%)$ & $10(41.7 \%)$ & $9(56.3 \%)$ & 0.36 \\
\hline Dyslipidemia & $16(17.4 \%)$ & $11(45.8 \%)$ & $5(31.3 \%)$ & 0.35 \\
\hline DM & $21(52.5 \%)$ & $11(45.8 \%)$ & $10(62.5 \%)$ & 0.30 \\
\hline $\begin{array}{l}\text { Hypertension } \\
\text { Comorbidities } \\
\end{array}$ & $25(62.5 \%)$ & $14(58.3 \%)$ & $11(68.8 \%)$ & 0.50 \\
\hline $\begin{array}{l}22 \text { comorbidities } \\
\text { Admission category }\end{array}$ & $13(32.5 \%)$ & $7(29.2 \%)$ & $6(37.5 \%)$ & 0.58 \\
\hline $\begin{array}{l}\text { Medical } \\
\text { Infection category }\end{array}$ & $34(85 \%)$ & $20(83.3 \%)$ & $14(87.5 \%)$ & 0.71 \\
\hline $\begin{array}{l}\text { Hospital acquired } \\
\text { Source of infection }\end{array}$ & $21(52.5 \%)$ & $12(50 \%)$ & $9(56.3 \%)$ & 0.62 \\
\hline Abdominal & $4(10 \%)$ & $3(12.5 \%)$ & $1(6.25)$ & 0.33 \\
\hline Respiratory & $20(50 \%)$ & $9(37.5 \%)$ & $11(68.75 \%)$ & 0.056 \\
\hline Skin, soft tissues & $3(7.5 \%)$ & $3(12.5 \%)$ & 0 & 0.23 \\
\hline
\end{tabular}

\begin{tabular}{|l|c|c|c|c|}
\hline Mixed & $10(25 \%)$ & $4(16.7 \%)$ & $6(37.5 \%)$ & 0.10 \\
Pthers & $3(7.5 \%)$ & $2(8.3 \%)$ & $1(6.25 \%)$ & 0.83 \\
Positive cultures & & & & \\
\hline Gram +ve bacteria & $4(10 \%)$ & $3(12.5 \%)$ & $1(3.10 \%)$ & 0.51 \\
Gram -ve only bacteria & $18(45 \%)$ & $15(62.5 \%)$ & $3(18.8 \%)$ & $\mathbf{0 . 0 0 6}^{*}$ \\
Polymicrobial & $18(45 \%)$ & $8(33.33 \%)$ & $10(62.5 \%)$ & 0.06 \\
\hline Hemoglobin gm/dL & & $10.52 \pm 3.46$ & $10.87 \pm 2.80$ & 0.74 \\
TLC n & & $23.00 \pm 12.9$ & $22.04 \pm 13.51$ & 0.82 \\
Albumin gm/dL & & $3.10 \pm 0.78$ & $3.17 \pm 1.04$ & 0.81 \\
Creatinine gm/dL & & $2.80 \pm 0.88$ & $1.40 \pm 0.66$ & $<\mathbf{0 . 0 0 1}^{*}$ \\
BUN gm/dL & & $46.41 \pm 11.5$ & $30.80 \pm 13.31$ & $<\mathbf{0 . 0 0 1}^{*}$ \\
Creatinine learance & & $38.11 \pm 10.5$ & $69.71 \pm 23.55$ & $<\mathbf{0 . 0 0 1}^{*}$ \\
\hline Mechanical ventilation & $18(45 \%)$ & $11(45.8 \%)$ & $7(43.7 \% 5)$ & 0.16 \\
Use of vasopressors & $25(62.5 \%)$ & $19(79.2 \%)$ & $6(37.5 \%)$ & $\mathbf{0 . 0 0 8}^{*}$ \\
History of ACE & $18(45 \%)$ & $13(54.16 \%)$ & $8(31.25 \%)$ & $\mathbf{0 . 0 4 1}^{*}$ \\
administration & & & & \\
\hline
\end{tabular}

BMI; body mass index, DM; diabetes mellitus, Blood Urea nitrogen, $p$-value significant $<\mathbf{0 . 0 5}$

In table 8, comparison between AKI and Non-AKI patients as regard variables of demographic, risk factors, comorbidities more than 2, admission category, infection category, positive cultures and source of infection, showed that there were no statistical significant differences between AKI and NonAKI patients except for; gender (male), BMI, gram -ve bacterial infection, creatinine, BUN, creatinine clearance, history of $\mathrm{ACE}$ administration and use of vasopressors were statistically significant $(\mathrm{p}<0.05)$.

\section{Table (9): Comparison between} comparison between AKI and Non-AKI patients as regard scores, ICU length of stay and mortality in the studied patients

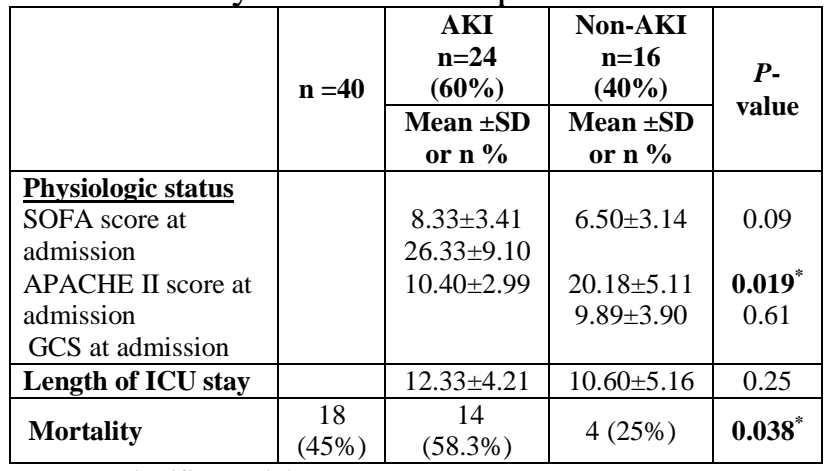

$p$-value significant $<0.05$

In table 9, comparison between AKI and Non-AKI patients was statistically significant as regard variables of APACHE II score at admission $(26.33 \pm 9.10$ vs $20.18 \pm 5.11)$ and mortality14 $(58.3 \%)$ vs 4 (25\%), they were significantly higher in AKI patients ( $p$-value $<0.05)$. There were no statistical significant differences between AKI and Non-AKI patients as regard SOFA score, GCS and length of ICU stay $(\mathrm{p}<0.05)$. 
Table (10): Multivariate regression analysis as regard $\mathrm{AKI}$

\begin{tabular}{|c|c|c|c|}
\hline Clinical Parameters & $\begin{array}{l}\text { Odd's } \\
\text { ratio }\end{array}$ & $\begin{array}{c}95 \% \\
\text { Confidence } \\
\text { Interval }\end{array}$ & $\begin{array}{c}\text { P- } \\
\text { value }\end{array}$ \\
\hline Gender (male) & 1.38 & $0.23-1.56$ & 0.24 \\
\hline $\mathrm{BMI} \geq 24 \mathrm{~kg} / \mathrm{m} 2$ & 2.82 & $0.45-5.72$ & $0.039 *$ \\
\hline Gram negative culture & 7.42 & $0.211-11.24$ & $0.006^{*}$ \\
\hline $\begin{array}{c}\text { History of ACE } \\
\text { administration }\end{array}$ & 4.22 & $0.741-5.13$ & $0.037 *$ \\
\hline $\begin{array}{c}\text { Creatinine clearance } \\
\text { at admission }>30 \\
\mathrm{~mL} / \mathrm{min} / 1.73 \mathrm{~m} 2\end{array}$ & 14.35 & $0.366-19.31$ & $<0.001 *$ \\
\hline $\begin{array}{c}\text { Creatinine at } \\
\text { admission }>2.26 \mathrm{mg} / \mathrm{dl}\end{array}$ & 16.17 & $0.507-21.74$ & $<0.001 *$ \\
\hline $\begin{array}{c}\text { BUN at } \\
\text { admission }>46.5 \mathrm{mg} / \mathrm{dl}\end{array}$ & 0.45 & $0.257-0.939$ & 0.50 \\
\hline Vasopressors use & 7.11 & $1.62-10.47$ & $0.008^{*}$ \\
\hline APACHII score (points) & 3.75 & $0.855-11.02$ & 0.053 \\
\hline
\end{tabular}

In table 17, multivariate regression analysis of several variables in this study shows statistically significant differences and there were independent predictors for acute kidney injury as follow: $\mathrm{BMI}(\mathrm{R}=2.82, \mathrm{CI}$ : 0.45 - 5.72) and $\mathrm{p}=0.039$, history of ACE administration ( $\mathrm{R}=4.22$, CI: $0.741-5.13)$ and $\mathrm{p}=0.037$, Gram negative culture $(\mathrm{R}=7.42, \mathrm{CI}$ : 0.211-11.24; $\mathrm{p}=0.006$ ), Creatinine clearance ( $\mathrm{R}=14.35$ ， CI: $0.366-19 . \quad 31 ; \quad \mathrm{p}<0.001)$, Creatinine ( $\mathrm{R}=16.7, \quad \mathrm{CI}:$ 0.507- 21.743; $\mathrm{p}<0.001)$,Vasopressors use ( $\mathrm{R}=7.11$, CI: 1.62 - 10.47; $\mathrm{p}=0.008)$ and Adequate resuscitation $(\mathrm{R}=13.013$, CI: 1.73 - $15.82 ; \mathrm{p}=0.01)$.

\section{DISCUSSION}

AKI is a serious complication in critically ill patients because AKI strongly affects outcomes such as mortality and medical costs ${ }^{(\mathbf{1})}$.

Sepsis is the most common contributing factor for the development of AKI. In adult and pediatric data, sepsis accounts for $26 \%$ to $50 \%$ of all AKI in developed nations, compared with $7 \%$ to $10 \%$ of primary kidney disease-associated AKI. Clinical and basic science evidence indicates that sepsis-associated AKI (SA-AKI) is distinct from AKI without sepsis, driven by a number of characteristic pathophysiological mechanisms, carrying a unique profile of timing (onset, duration), and being associated with different short-and long-term outcomes (2)
Septic acute kidney injury (AKI) is a syndrome of acute impairment of function and organ damage linked with long-term adverse outcomes depending on the extent of acute injury superimposed on underlying organ reserve. Implicit in this concept is that dysfunction should be reversible and rescue is possible, but that duration of the insult and underlying renal reserve may limit restoration of renal function. Thus, septic AKI is a clinical diagnosis based on specific, contextdependent, and imperfect definitions ${ }^{(3)}$; with azotemia and oliguria still its key diagnostic criteria $^{(4)}$.

Our study was a prospective randomized study that was conducted on patients who were admitted to ICU in Ain Shams University Hospitals. Forty patients were included in this study and an informed written consent was obtained from patients and /or relatives. All patients were adult, more than 18 years old, admitted to ICU suffering from severe sepsis or had septic shock. Our aim was to show the incidence and prognosis of acute renal failure in patients with sepsis and septic shock.

In the current study, the mean age of patients included in this study was $58.37 \pm$ 15.66 years. 23 patients $(57.5 \%)$ were males and 17 patients $(42.5 \%)$ were females. The most frequent risk factors were hypertension $(62.5 \%)$ followed by diabetes $(52.5 \%)$ beside other risk factors as smoking and dyslipidemia. Risk factors in our study were great contributors to patients at risk of sepsis showed by several studies:

Demographic features in our study were in accordance with several studies as Zanon et al. ${ }^{(10)}$ who in their study found that mean age was $60.7 \pm 18.6$ years, and $56.8 \%$ of the patients were older than 60 years; $55.5 \%$ were men. These findings are closer to our findings as regard mean age. Also, Ortíz et al. (11) found that the average age of the population under their study was $54.5 \pm 20$ years. There were no great differences regard age or gender with our findings.

Patients at high risk of sepsis associated acute kidney injury (SA-AKI) have been identified. Elderly patients carry a higher incidence rate of SA-AKI ${ }^{(11)}$. 
As regard risk factors, Wang et al. ${ }^{(12)}$ stated that the risk of incident sepsis was higher among older individuals. While both current and past tobacco use were associated with increased incident sepsis risk. Also, Mayr et al. ${ }^{(13)}$ reported that most of the risk factors of severe sepsis were age, male gender, black race, and increased burden of chronic health conditions. Also, they found that the incidence of severe sepsis increases disproportionately in older adults, and more than half of severe sepsis cases occur in adults over 65 y of age.

Cowie et al. ${ }^{(14)}$ reported that diabetes mellitus is a highly prevalent condition associated with both AKI and sepsis. Esper $\boldsymbol{e t}$ al. ${ }^{(15)}$ assessed the impact of having diabetes on the risk of AKI during sepsis. Yegenaga $\boldsymbol{e t}$ al. (16) reported that diabetes itself may also increase the risk of AKI during sepsis.

In this study, comorbidities in the studied patients were mostly COPD or chest diseases $25 \%$, previous surgery $7.5 \%$, liver disease $7.5 \%$ and the least comorbidity was malignancy $5 \%$. Similarly, all of the chronic medical conditions included in the study of Wang et al. (12) were analyzed and they exhibited significant adjusted associations with incident sepsis. Chronic lung disease and chronic kidney disease exhibited the strongest adjusted associations with incident sepsis. The risk of incident sepsis was associated with the number of chronic medical conditions $(\mathrm{p}=0.001)$. Baseline comorbidities, specifically chronic kidney disease, diabetes mellitus, heart failure, malignancy, and liver disease increase patients' susceptibility to SA$\mathrm{KI}^{(16)}$.

Mayr et al. ${ }^{(13)}$ reported that severe sepsis is more likely to occur in individuals with chronic obstructive pulmonary disease, cancer, chronic renal and liver disease, and diabetes. Other risk factors include residence in long-term care facilities, malnutrition, and use of immunosuppressive medications and prosthetic devices.

In the current study, sources of infection in the studied patients were mostly respiratory $50 \%$ then mixed $25 \%$ and the least sources of infection were abdominal $10 \%$, skin and soft tissues $7.5 \%$ and others (infection from central venous line) $7.5 \%$.
This was in accordance with Zanon $\boldsymbol{e t}$ al. (10) who stated that the most frequent sites of infection were the lungs $(71.6 \%)$. Of all study patients, 414 (73.9\%) developed infection; cultures were made for $340(60.7 \%)$ and were positive in $50.3 \%$ of the cases. Hoste et al. ${ }^{(17)}$ found that the lung, followed by the abdomen and urinary tract, were common sources of infection in ICU. Similarly, Esper et al. (15) found that respiratory tract infections, particularly pneumonia, are the most common site of infection, and associated with the highest mortality. Men are particularly prone to develop pneumonia, (15) while genitourinary infections are more common among women ${ }^{(\mathbf{1 5})}$. Other common sources of infection include abdominal, skin, and soft tissue, device-related, central nervous system, and endocarditis ${ }^{(\mathbf{1 5})}$.

Sources of sepsis, in particular, blood stream infection, abdominal and genitourinary sepsis, and infective endocarditis, are associated with a higher likelihood of developing AKI. Similar to the poor outcome of patients with sepsis, delayed administration of appropriate antimicrobial therapy was shown to be an independent predictor of the development of AKI. Incremental delays in antimicrobial delivery after the onset of hypotension showed a direct relationship with the development of $\mathrm{AKI}{ }^{(17)}$.

In this study, infection in the studied patients were mostly gram -ve only $21(45.6 \%)$ and poly-microbial $20(43.47 \%)$. The least were gram +ve only $5(10.9 \%)$. In gram positive bacteria, staphylococcus aureus and streptococcus pneumonia were more prevalent $(7.5 \%$ and $10 \%$ respectively), MRSA, staphylococcus epidermidis 5\% each, and enterococcus and others were $2.5 \%$ each. In gram negative bacteria, Escherichia coli and Klebsiella species were more prevalent (27.5\% and 25\% respectively). Pseudomonas species, Proteus mirabilis, Acinetobacter species, Haemophilus influenza, Enterobacter and others were $20 \%, 10 \%, 5 \%, 5 \%, 2.5 \%$ and $2.5 \%$ respectively. Fungal infection was caused by candida in $17.5 \%$ patients. Also, same findings were similar to us in several studies:

In Zanon et al. (10) study, the most frequent pathogens were gram-negative 
bacilli (Escherichia coli, Pseudomonas aeruginosa, Enterobacter and Acinetobacter) in $53.2 \%$ of the cases, and gram-positive cocci (coagulase-negative staphylococcus and staphylococcus aureus). More than one pathogen was identified in $2.8 \%$ of the cases, and fungi, in $1.3 \%$.

In the study of Vincent et al. (18), patterns of infecting organisms were with predominant organisms being staphylococcus aureus (20.5\%), pseudomonas species (19.9\%), Enterobacteriaceae (mainly E. coli, $16.0 \%)$, and fungi (19\%). Acinetobacter was involved in $9 \%$ of all infections, with significant variation of infection rates across different regions $3.7 \%$ in North America vs $19.2 \%$ in Asia).

In Huang et al. ${ }^{(19)}$ study, out of 269 patients with documented microbiological results, Gram-negative bacteria, Grampositive bacteria, and fungi were isolated in $65 \%, 25 \%$, and $10 \%$ of the severe sepsis patients. The most prevalent species were Klebsiella pneumoniae $(8.6 \%)$, Escherichia coli $(6.0 \%)$, Acinetobacter baumannii $(5.6 \%)$, pseudomonas aeruginosa $(5.4 \%)$, and enterococcus species $(4.5 \%)$.

In this study, means of SOFA score at admission was $7.6 \pm 3.11$ (Points). Mean of APACHE II score at admission was 23.87 \pm 8.26 (Points).

Studies in Europe and the US with patients with sepsis reported general mortality rates that ranged from $13.5 \%$ to $53.6 \%{ }^{(20)}$.

Ferreira et al. ${ }^{(21)}$ reported that the mean SOFA score in survivors was $3.48 \pm$ 2.238 and in non-survivors was $8.9 \pm 3.45$ and the difference was statistically significant.

In our study, the incidence of AKI was $24(60 \%)$ and non-AKI were $16(40 \%)$ of the studied patients. Mean length of ICU stay was $9.85 \pm 6.37$ days. Our study was in range with several studies. De Boer et al. ${ }^{(22)}$ reported that among patients admitted to the ICU, 35\% to $70 \%$ develop AKI, which was related to sepsis in half the cases. AKI has been reported in $19 \%$ of patients with sepsis, $23 \%$ of those with severe sepsis, and $51 \%$ of those with septic shock and bacteremia.

Bagshaw et al. (23) reported that the causative relationship between sepsis and AKI is firmly established and the incidence of AKI is high even among patients with no severe infections or shock ${ }^{(35)}$. A recent retrospective multicenter study of 4532 patients with septic shock admitted to 22 ICUs over 16 years reported development of early AKI in $64.4 \%$ of patients.

In general ICU patients, the incidence of AKI varies from $6 \%$ up to $67 \%$ depending on the study population ${ }^{(24)}$. Among critically ill patients the etiology of AKI is multifactorial and severe sepsis is the most common contributing factor to AKI. Of critically ill patients with AKI, 20\%-67\% have concomitant sepsis, severe sepsis, or septic shock ${ }^{(23)}$.

The FINNAKI study (2012), covering $85 \%$ of the adult population in Finland, reported the population-based incidence of ICU-treated AKI as 0.746/1000 adult population/year (23). Previously only two studies have reported the population-based incidence of ICU-treated AKI to be $2.147 / 1000$ adult population/year and 2.9/1000 adult population/year ${ }^{\text {(24) }}$.

De Boer et al. (21) stated that the development of AKI during sepsis has been reported to increase mortality and hospital stay length.

In our study, mean length of ICU stay was higher in AKI than non-AKI but without statistical significance. In accordance with Hoste et $\boldsymbol{a l} .{ }^{(17)}$, they stated that length of stay is longer in patients with SA-AKI versus AKI without sepsis or sepsis alone. Septic patients developing AKI were found to have twice the duration of ICU stay compared with septic patients without AKI. Moreover, there was a stepwise increase of length of stay according to AKI severity.

In our study, comparison between AKI and Non-AKI patients as regarding several variables showed that there was statistical significant differences between AKI and Non-AKI patients as regard; gender (male), BMI, Renal source of infection, gram -ve bacterial infection, creatinine, BUN, history of ACE administration, creatinine clearance, use of vasopressors which were statistically significant $(\mathrm{p}<0.05)$. Multivariate regression analysis showed that they were independent predictors for acute kidney injury as follow: BMI, Gram negative 
culture, history of ACE administration, creatinine clearance, creatinine, Vasopressors use and adequate resuscitation.

In agreement with our study, higher BMI has been linked to renal failure ${ }^{(25)}$ and has been shown to be an independent risk factor for developing AKI in ICU patients in general ${ }^{\text {(26) }}$.

Similar to the findings of Bagshaw et al. (22) there was no difference in age or chronic co morbidities (hypertension and diabetes mellitus between patients who did and did not develop AKI. Evidence addressing the relationship between AKI and source of infection are diverse ${ }^{(25)}$.

As regard association of AKI with positive blood cultures by gram-ve bacteria were independent factors, in contrary to our findings, Plataki et al. ${ }^{(27)}$ found that intraabdominal source of sepsis was an independent risk factor for AKI. This may be due to higher prevalence of intra-abdominal infection and low sample size.

Bentley et al. (28) reported that ACEI/ARB use was an independent predictor of AKI. In situations like shock that involve a reduction in renal perfusion; these drugs will further decrease intraglomerular pressure. This was in accordance with our findings as regards history of ACE administration.

\section{CONCLUSION}

The incidence of AKI was $60 \%$ of patients in our study. The development of septic AKI adversely affected clinical outcomes. Moreover, the severity of AKI was associated with increased short-term mortality as observed in ICU patients. The study showed that there were no statistical significant differences between AKI and NonAKI patients except for; gender (male), BMI, gram -ve bacterial infection, creatinine, BUN, creatinine clearance, history of ACE administration, use of vasopressors, APACHE II score at admission and mortality.

\section{REFERENCES}

1) Poukkanen M, Vaara ST, Pettilk V, Kaukonen KM, Korhonen AM, Hovilehto S et al. (2013): Acute kidney injury in patients with severe sepsis in Finnish Intensive Care Units. Acta Anaesthesiol Scand., 57:863-872.
2) Uchino S, Kellum JA, Bellomo R, Doig GS, Morimatsu $\mathrm{H}$, Morgera $\mathrm{S}$ et al. (2005): Acute renal failure in critically ill patients: a multinational, multicenter study. JAMA., 294:813-818.

3) Bagshaw SM, Uchino S, Bellomo R, Morimatsu H, Morgera S, Schetz M (2007): Beginning and Ending Supportive Therapy for the kidney (BEST Kidney) Investigators et al. Septic acute kidney injury in critically ill patients: clinical characteristics and outcomes. Clin J Am Soc Nephrol., 2:431-439.

4) Deutschman, CS; Tracey, KJ (2014): "Sepsis: Current dogma and new perspectives". Immunity, 40(4):463-75.

5) Singer M, Deutschman CS, Seymour CW et al. (2016): The third international consensus definitions for sepsis and septic shock (Sepsis-3). JAMA., 315:801-810.

6) Rhodes A, Evans LE (2017): Surviving Sepsis Campaign: International Guidelines for Management of Sepsis and Septic Shock. Crit Care Med; 45(3): 486-552.

7) KDIGO AKI Work Group (2012): KDIGO clinical practice guideline for acute kidney injury. Kidney Int (Suppl)., 17:1138.

8) Knaus WA, Draper EA, Wagner DP, Zimmerman JE (1985): APACHE II: a severity of disease classification system. Crit Care Med., 13:818-829.

9) Vincent JL, Moreno $\mathrm{R}$, Takala $\mathrm{J}$ et al. (1996): The SOFA (Sepsis related organ failure assessment) score to describe organ dysfunction or failure: on behalf of the working group on sepsis related problems of the European society if Intensive care medicine. Intensive Care Med., 22:707-710.

10) Zanon F, Caovilla JJ, Michel RC, Cabeda EV, Ceretta DF, Luckemeyer GD, Beltrame C, Naiana Posenatto (2008): Sepsis in the Intensive Care Unit: etiologies, Prognostic Factors and Mortality. Rev Bras Ter Intensiva., 20(2):128-134.

11) Ortíz G, Dueñas C, Rodrí, Barrera $L$, de La Rosa G, Dennis R, M Granados, Londoño D, Molina F,Jaimes F (2014): Epidemiology of sepsis in Colombian intensive care units. Biomédica, 34:40-47.

12) Wang HE, Shapiro NI, Griffin R, Safford MM, Judd S and Howard G (2012): Chronic Medical Conditions and Risk of Sepsis. PLoS ONE, 7(10):220-250.

13) Mayr FB, Yende S, Linde-Zwirble WT, Peck- Palmer OM, Barnato AE, Weissfeld LA, Angus DC (2010): Infection rate and acute organ dysfunction risk as explanations for racial differences in severe sepsis. JAMA., 303:2495-503.

14) Cowie CC, Rust KF, Byrd-Holt DD, Gregg EW, Ford ES, Geiss LS et al. (2010): Prevalence of diabetes and high risk 
for diabetes using A1c criteria in the US population in 1988-2006. Diabetes Care, 33(3):562-568.

15) Esper AM, Moss M, Martin GS (2009): The effect of diabetes mellitus on organ dysfunction with sepsis: an epidemiological study. Crit Care, 13(1):R18.

16) Yegenaga I, Hoste E, Van Biesen W, Vanholder R, Benoit D, Kantarci G et al. (2004): Clinical characteristics of patients developing ARF due to sepsis/systemic inflammatory response syndrome: results of a prospective study. Am J Kidney Dis., 43(5):817-824.

17) Hoste EA, Lameire NH, Vanholder RC, Benoit DD, Decruyenaere JM, Colardyn FA (2003): Acute renal failure in patients with sepsis in a surgical ICU: predictive factors, incidence, comorbidity, and outcome. J Am Soc Nephrol., 14:10221030.

18) Vincent JL, Rello J, Marshall J, Silva E, Anzueto A, Martin CD, Moreno R, Lipman J, Gomersall C, Sakr Y et al. (2009): EPIC II Group of Investigators. International study of the prevalence and outcomes of infection in intensive care units. JAMA., 302:2323-2329.

19) Huang CT, Tsai YJ, Tsai PR, Yu CJ, and Wen-Je Ko (2015): Epidemiology and Outcome of Severe Sepsis and Septic Shock in Surgical Intensive Care Units in Northern Taiwan. Medicine, 94(47):e2136.

20) Engel C, Brunkhorst FM, Bone HG et al. (2007): Epidemiology of sepsis in Germany: results from a national prospective multicenter study. Intensive Care Med., 33:606-618.

21) Ferreira FL, Bota DP, Bross A, Mélot $\mathrm{C}$, Vincent JL (2001): Serial evaluation of the SOFA score to predict outcome in critically ill patients. JAMA., 286:1754-1788.

22) De Boer IH, Rue TC, Hall YN, Heagerty PJ, Weiss NS, Himmelfarb J (2011): Temporal Trends in the Prevalence of Diabetic Kidney Disease in the United States. JAMA., 305(24):220-245.

23) Bagshaw SM, Lapinsky S, Dial S, Arabi Y, Dodek P, Wood G et al. (2009): Cooperative Antimicrobial Therapy of Septic Shock Database Research Group: Acute kidney injury in septic shock: clinical outcomes and impact of duration of hypotension prior to initiation of antimicrobial therapy. Intensive Care Med., 35:871-881.

24) Murugan R, Karajala-Subramanyam V, Lee M, Yende S, Kong L, Carter $M$, Angus DC, Kellum JA (2010): Acute kidney injury in non-severe pneumonia is associated with an increased immune response and lower survival. Kidney Int., 77:527-535.
25) Piccinni P, Cruz DN, Gramaticopolo S, Garzotto F, Dal Santo M, Aneloni G, Rocco M et al. (2011): NEFROINT Investigators. Prospective multicenter study on epidemiology of acute kidney injury in the ICU: a critical care nephrology Italian collaborative effort (NEFROINT). Minerva Anestesiol. 77:1072-1083.

26) Fujii $T$, Uchino $S$, Takinami $M$, Bellomo R (2014): Validation of the kidney disease improving global outcomes criteria for AKI and comparison of three criteria in hospitalized patients. Clin J Am Soc Nephrol., 9:848-854.

27) Plataki M, Kashani K, Cabello-Garza J, Maldonado F, Kashyap R, Kor DJ, Gajic O, Cartin-Ceba R (2011): Predictors of Acute Kidney Injury in Septic Shock Patients: An Observational Cohort Study. Clin J Am Soc Nephrol., 6:1744-1751.

28) Bentley ML, Corwin HL, Dasta J (2010): Drug-induced acute kidney injury in the critically ill adult: recognition and prevention strategies. Crit Care Med., 38:169-174.

29) Schneider AG, Bellomo R, Bagshaw SM, Glassford NJ, Lo S, Jun M, et al. (2013): Choice of renal replacement therapy modality and dialysis dependence after acute kidney injury: a systematic review and meta-analysis. Intensive Care Med; 39:987997. 